\title{
Modified Fuzzy Logic Based Control Strategy for Grid Connected Wind Energy Conversion System
}

\author{
Velappagari Sekhar and Ramesh Babu N* \\ School of Electrical Engineering, VIT University, Vellore, India-632014 \\ E-mail:velappagarisekhar@gmail.com; nrameshbabu@vit.ac.in \\ *Corresponding Author
}

Received 23 November 2016; Accepted 24 May 2017;

Publication 2 June 2017

\begin{abstract}
This paper analyses the modelling and control of the grid connected wind energy conversion system (WECS). The required power for grid connected load is effectively supplied by the proposed wind turbine, permanent magnet. And at the grid connected voltage source inverter utilizes a simple FLC with hysteresis current controller (HCC), which suits well for variable speed operation of a wind turbine with direct driven PMSG. Detailed modelling and controller strategies of overall system performance during the transient and dynamic conditions of the proposed system are analyzed to show the effectiveness of the controller strategies. The simulations have been done using MATLAB/Simulink.
\end{abstract}

Keywords: Permanent magnet synchronous generator (PMSG), State of charge (SOC), Fuzzy logic controller (FLC), Hysteresis current controller (HCC), Boost converter, Voltage source inverter (VSI), Smart grid.

\section{Introduction}

Recently with the increase in power demand, continuing threat of global warming and the extinction of fossil fuel, many power producers are finding sustainable green energy as a solution to preserve the resources for the future.

Journal of Green Engineering, Vol. 6_4, 369-384.

doi: 10.13052/jge1904-4720.642

(C) 2017 River Publishers. All rights reserved. 
Among the renewable energy sources, wind energy and solar PV based power production are preferred as it is abundantly available globally. Wind energy is capable to supply large power production compare to other renewable sources $[1,2]$. In the past 10 years wind energy conversion systems had continues growth and at the end the year 2014 the cumulative installed stand at 369,597 MW, at the average cumulative growth rate around $44 \%$ and in 2015 it is reached 53GW capacity installation. At the end of the 2016 the cumulative capacity growth has been forecasted to $14.5 \%$ globally [1].

Among all available wind energy conversion systems, wind turbines with direct drive PMSG plays important role, due to its higher efficiency and reduced maintenance cost. Whereas in asynchronous generator when the capacity of the wind turbine is large tends to the greater inertia and the addition of fly wheels, gear boxes for overcome wind fluctuations will tends to decreases efficiency [2]. Resuscitate the operating mode, variable speed WECS is the preponderating technology in the current wind power industry, as it has several merits over the fixed speed WECS such as: maximum power output from varying wind speed, high efficiency and low mechanical stress $[2,3]$.

The success of WECS based power production completely depends on appropriate controller techniques implemented on the rectifier and the inverter. The researchers focus on various controller designs in order to improve the self-consumption losses, nonlinearity, output fluctuation and harmonic distortion. Hence inverter design plays a very important role. In WECS overall performance, due to larger filter size and lack of the intelligence level, conventional proportional integral (PI), proportional integral derivative (PID), proportional resonant integral (PRI) and quasi-proportional resonance (QPR) controls methods are not being effective. Hence researchers are tending to use intelligent controllers like fuzzy logic controllers (FLC), neural networks, adaptive neuro fuzzy interfacing system (ANFIS) and genetic algorithm (GA) [4-6]. Smart grid requires a fast convergence of error, grid fault and power balance to supply uninterrupted power supply to the consumers [7-9], thus soft computing techniques are generally employed to support these parameters.

However the fuzzy controller is robust and need not require the mathematical model of the controlled object. In this paper, fuzzy based controllers for inverters and rectifier boost controllers is developed. The developed fuzzy based control strategy provides better performance in reducing the overshoots of both output voltage and current when compared to conventional controllers [10-12]. 


\section{System Modelling}

A two bladed wind turbine with fixed pitch directly transmits the developed aerodynamic torque and mechanical power to the PMSG.The power generated from the PMSG is then fed to the utility AC grid through a converter and inverter as shown in Figure 1. The generator voltage from PMSG is fed to the diode bridge rectifier and the output DC voltage is stepped up by the fuzzy controlled boost converter. The resultant DC energy is inverted and integrated to the AC grid through voltage source inverter (VSI) with fuzzy logic based hysteresis current controller (HCC). The HCC controller plays an important role in unconditioned stability and non-linear system. They have very fast response and high quality precision. HCC derives the switching pattern for the inverter in such a way that the current error is drastically reduced [13].

\subsection{System Modelling}

The wind turbine extracts the energy from the moving air. The power in the air for blade swept area A is estimated by [14],

$$
P_{m}=\frac{1}{2} C_{p}(\beta, \lambda) \rho \pi R^{2} V_{w i n d}^{3}
$$

Where,

$\mathrm{Pm}:$ output power,

$C_{P}$ : rotor power coefficient,

$\beta$ : blade pitch angle,

$\lambda$ : Tip Speed Ratio (TSR),

$\rho:$ air density,

$\mathrm{R}$ : radius of wind turbine blade and

$\mathrm{V}_{\text {wind }}$ : wind speed.

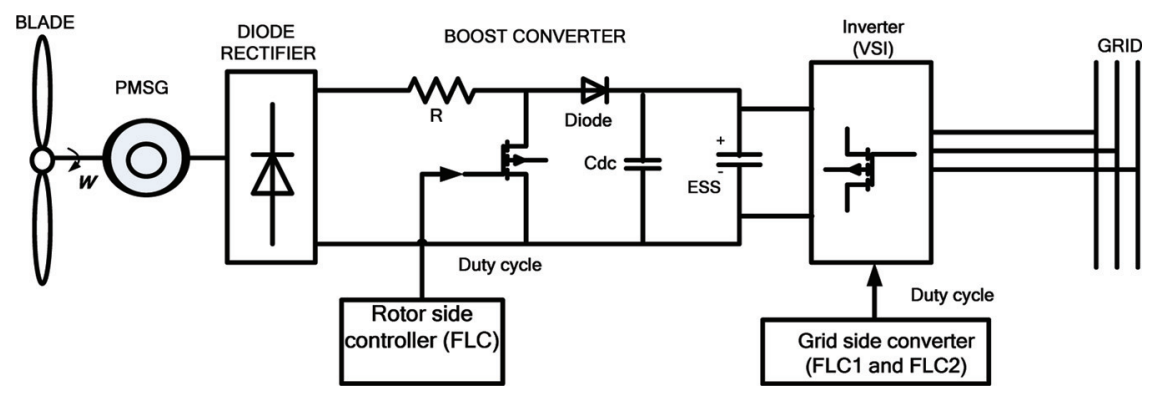

Figure 1 Grid connected PMSG Configuration. 
The rotor power coefficient $C_{P}$ defines the quantum of available wind power that can be transferred into mechanical power and it is a function. The power coefficient of wind turbine is determined by TSR. However, the $C_{P}$ in general blade design is provided by the manufacturer [15].

The power coefficient $C_{P}$ is defined as, the ratio between the mechanical power generated and the available wind power in air stream which passes through same area, and expressed as,

$$
C_{p}=\frac{P_{\text {mech }}}{P_{\text {wind }}}
$$

The $C_{P}$ is a function of tip speed ratio $\lambda$ and blade pitch angle $\beta$.

$$
\lambda=\frac{u}{\nu_{1}}=\frac{\omega R}{\nu_{1}}
$$

where,

$\mathrm{u}:$ tangential velocity of the blade pitch,

$\omega:$ angular velocity of the rotor, and

$\mathrm{R}$ : rotor radius in meters, $\mathrm{v} 1$ is the wind velocity.

Using the power coefficient, the mechanical power on the rotor can be,

$$
P_{R}=C_{p} \frac{1}{2} \rho A V_{w i n d}^{3}
$$

And the mechanical torque on rotor can be

$$
T_{\text {mech }}=\frac{P_{R}}{\omega_{R}}
$$

where,

$\omega_{R}:$ rotor angular speed,

$P_{R}$ : rotor mechanical power,

$T_{m e c h}:$ mechanical torque in the rotor,

$A$ : the swept area of rotor.

Thus the rotor mechanical torque is a function of rotor mechanical power which is function of power coefficient $C_{P}$.

\subsection{Grid Connected PMSG Modeling}

The analysis of PMSG system is analyzed using Park's transformation, where phase quantities like stator voltage, current which are time varying quantities were transformed to dq axis and they are not dependent on time $[16,17]$. 
The abc to dq0 transformation can be expressed as [16]

$$
\begin{aligned}
& u_{d}=R_{i d}+L_{d} i_{d}^{*}-\phi_{q} \omega_{s} \\
& u_{q}=R_{i q}+L_{q} i_{q}^{*}-\phi_{d} \omega_{s}
\end{aligned}
$$

where,

$\mathrm{R}$ : stator resistance, $\mathrm{u}_{d}, \mathrm{u}_{q}: \mathrm{d}-\mathrm{q}$ axis stator voltages, $\mathrm{L}_{d}, \mathrm{~L}_{q}$ : $\mathrm{d}-\mathrm{q}$ axis inductances and $\omega_{s}$ : stator frequency.

$$
\begin{gathered}
\phi_{d}=L_{d} i_{d}+\phi_{m} \\
\phi_{q}=L_{q} i_{q}
\end{gathered}
$$

$\phi_{d}$ and $\phi_{q}: \mathrm{d}$ and $\mathrm{q}$ axis fluxes and $\phi_{m}$ : constant flux due to permanent magnets.

Thus, the model at Equation (6) and Equation (7) becomes,

$$
\begin{gathered}
u_{d}=R i_{d}+L_{d} i_{d}^{*}-L_{q} i_{q} \omega_{s} \\
u_{q}=R i_{q}+L_{q} i_{q}^{*}-\left(L_{d} i_{d}+\phi_{m}\right) \omega_{s}
\end{gathered}
$$

The electromagnetic torque $\left(\Gamma_{G}\right)$ is obtained as

$$
\Gamma_{G}=p\left(\phi_{d} i_{q}-\phi_{q} i_{d}\right)=p\left(\phi_{m} i_{q}+\left(L_{d}-L_{q}\right) i_{d} i_{q}\right)
$$

where, p: number of pole pairs. If the permanent magnets are mounted on the rotor surface, then $\mathrm{L}_{\mathrm{d}}=\mathrm{L}_{\mathrm{q}}$ and the electromagnetic torque becomes,

$$
\Gamma_{G}=p \phi_{m} i_{q}
$$

When the PMSG operates as a grid connected generator, then Equation (13) and Equation (14) becomes,

$$
\begin{gathered}
u_{d}=-R i_{d}+L_{d} i_{d}^{*}+L_{q} i_{q} \omega_{s} \\
u_{q}=-R i_{q}-L_{q} i_{q}^{*}-\left(L_{d} i_{d}-\phi_{m}\right) \omega_{s}
\end{gathered}
$$

The stator frequency, $\omega_{s}$ is proportional to shaft speed, $\omega_{s}=p * \Omega_{h}$.

The grid connected generator torque which is proportional to the number of pole pairs. The PMSG generator does not require any drive train and they are used for variable speed variable pitch application. The parameters selected for PMSG is shown in Appendix A. 


\subsection{Boost Converter}

The boost converter is employed between rectifier capacitor and the battery and to step up the generated DC voltage. The voltage and current relation of the converter is given by $[18,19]$

$$
V_{o}=\frac{V_{d c}}{1-D}
$$

where, $\mathrm{D}$ is the duty cycle. When $\mathrm{V}_{d c} \geq \mathrm{V}_{o}$, the boost converter is not working, and the current provided by the generator is transmitted through the bypass diode Ds.

\subsection{Rotor Side Converter Controller}

The fuzzy logic based controller is employed in rotor side converter. FLC has an advantage of fast convergence, imprecise input and handling non linearity. FLC generally consist of three stages Fuzzification, Rule base lookup table and Defuzzification as shown in Figure 2. The rules are designed on the basis of previous knowledge of the system [14]. An FLC is the artificial decision making controller that operates in closed loop. The inputs for fuzzy controllers are error signal and change in error signal. Once the signals are calculated and

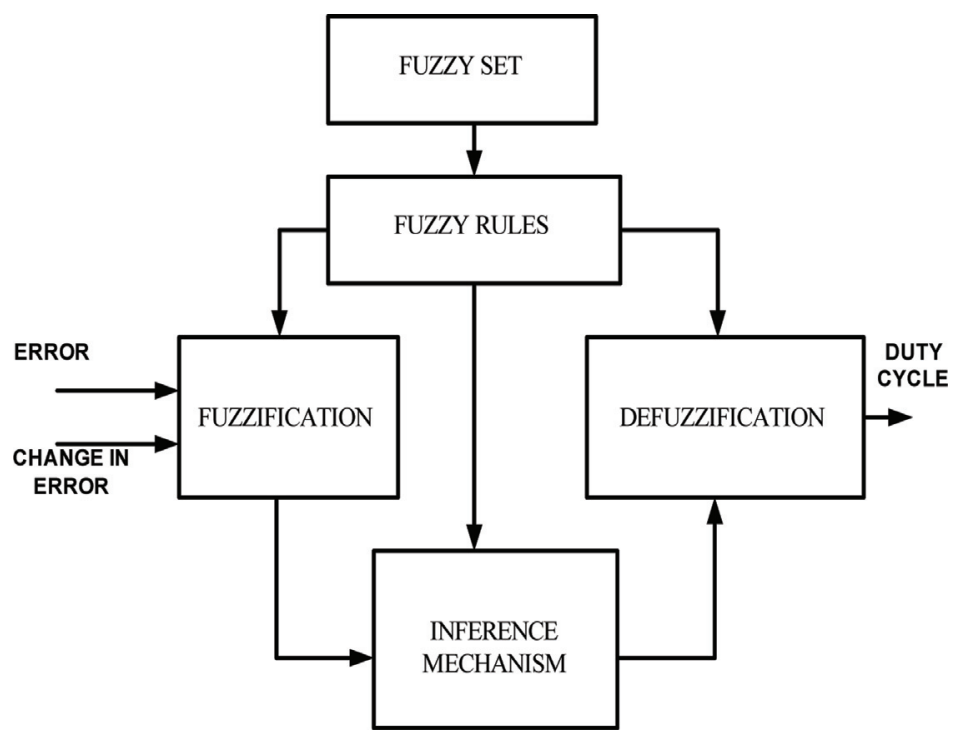

Figure 2 Basic structure of FLC. 
linguistic variables are obtained which determines the output variable based on the rules mechanism. The membership function of input and output variables decides the precision and convergence speed of any FLC controller. In this paper, Triangular membership function is used because; the implementation of triangular membership function is simple when compared to Gaussian and Trapezoidal membership function.

The input variables are the rate of change of DC power and rate of change of DC current as expressed in Equations (17) and (18) respectively and output variable of the FLC is the Change in DC voltage. These variables are represented in form of membership function as NL, NM, NS, ZO, PS, PM, PL. the fuzzification stage is employed with Sugeno's model and defuzzification utilizes the centre of gravity $(\mathrm{COG})$ to calculate the output variable value [20].

The basic principle of operation of FLC is shown in Figure 3. If the power increases with respect to the previous step voltage then the search process continues in the same direction, or else it will be reversed. So here there can be two input variables [21].

$$
\begin{aligned}
\Delta P_{d c} & =P_{d c}(k)-P_{d c}(k-1) \\
\Delta I_{d c} & =I_{d c}(k)-I_{d c}(k-1)
\end{aligned}
$$

where, $P_{d c}(k), I_{d c}(k), P_{d c}(k-1)$ and $I_{d c}(k-1)$ indicates the dc power and current at the time instants $\mathrm{k}, \mathrm{k}-1$ respectively.

The fuzzy mapping of input and output is carried based on Table 1. where $\left(\Delta \mathrm{V}_{d c}, \Delta \mathrm{P}_{d c}\right)$ are the input variables, $\Delta \mathrm{V}_{d c-o p t}$ is the control variable and NL, NM, NS, ZO, PS, PM, PL are the fuzzy sets.

Inference mechanism is basically defined by membership functions of FLC which determines the relevance of rules.

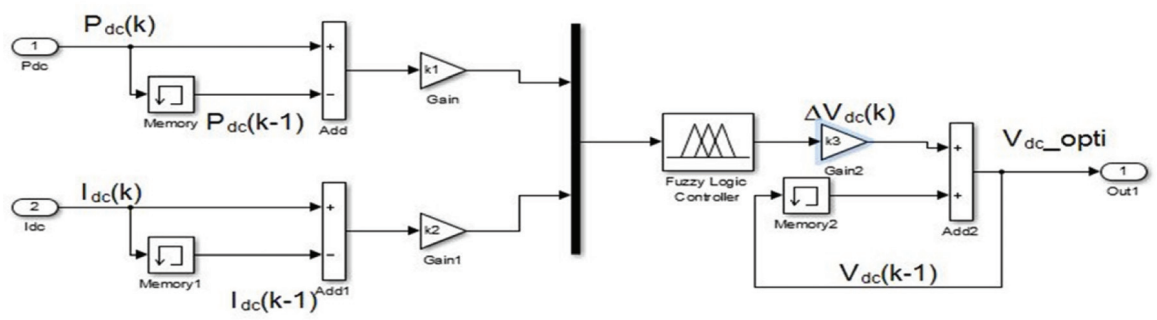

Figure 3 Block diagram of the fuzzy logic controller. 
Table 1 Fuzzy rule table for FLC in boost converter

\begin{tabular}{cllllllll}
\hline & \multicolumn{7}{c}{$\Delta P_{d c}$} \\
\cline { 2 - 8 }$\Delta V_{d c-o p t}$ & NL & NM & NS & ZO & PS & PM & PL \\
\hline$\Delta I_{d c}$ & NL & PL & PL & PM & PS & NL & NL & NL \\
NM & PM & PM & PM & ZO & NM & NM & NM \\
NS & PM & PM & PS & ZO & NS & NS & NM \\
ZO & NS & NS & NS & ZO & PS & PS & PS \\
PS & NM & NM & NM & ZO & PS & PS & PM \\
PM & NM & NL & NM & ZO & PM & PM & PM \\
PL & NL & NL & NL & NS & PL & PM & PL \\
\hline
\end{tabular}

\subsection{Grid Side Inverter (GSI)}

In this system, the grid side inverter (GSI) is controlled using FLC and hence it can deal the nonlinearity in power system in a wide operating range. The FLC controlled GSI is represented [21-24] as shown in Figure 4.

The VSI is connected to the grid without any transformer and the real power, $\mathrm{P}$ and reactive power, $\mathrm{Q}$ fed through VSI can easily be computed as,

$$
\left.\begin{array}{l}
P \alpha I_{d} \alpha-V_{c q} \\
Q \alpha I_{q} \alpha-V_{c d}
\end{array}\right\}
$$

where $\mathrm{I}_{q}, \mathrm{~V}_{c q}$ and $\mathrm{I}_{d}, \mathrm{~V}_{c d}$ are the quadrature and direct axis components of the current phasors and AC voltage of VSI output. The d-q quantity and 3-phase electrical quantity are relavent to each other through by reference frame transformation. And the angle of the transformation is absorbed from 3 -phase voltages on the high voltage grid terminal by using PLL.

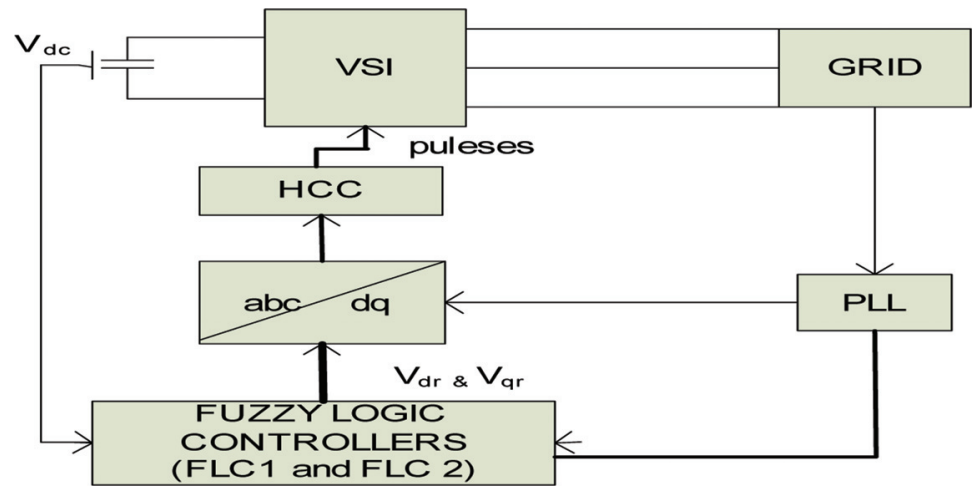

Figure 4 Schematic diagram of grid side inverter. 
By omitting switching losses and harmonics, Equation (19) is modified as,

$$
P \alpha V_{d c} I_{d c}
$$

where, $\mathrm{I}_{d c}$ and $\mathrm{V}_{d c}$ represents inverter DC voltage and DC current respectively.

Based on this logic, a simple control strategy is developed in this article for the grid side VSI as shown in Figure 5. The fuzzy controller produces the reference signals which generate gate pulses by using the hysteresis controller. The hysteresis current controller has been deployed because of its simple design, easy implementation, quick response, control of device peak current and its insensitivity nature with DC links voltage ripple.

In the controller block as shown in Figure 5, the error e 1 and derivative of its error e1 signal from AC grid voltage and the error e 2 and derivative of its error signal of e 2 from dc link voltages, which is applied to the proposed FLC system to find out the reference signals. To design the proposed FLCs, we require four inputs which are the error signals: e1 $(\mathrm{k})$ and e2(k) and the change of error signals: $e 1(k)$ and $e 2(k)$. The $\mathrm{d}-\mathrm{q}$ axis reference voltages, $\mathrm{V}_{d r}$ and $\mathrm{V}_{q r}$ are considered as the control output, which are the actual reference signals to produce the duty cycles for inverter.

For objective convenience the input and output variables of the FLCs are scaled with $k d 1, k d 2, k d 3, k q 1, k q 2$ and $k q 3$ as represented in Figure 5. Table 2 shows the rules of FLC 1 and FLC 2 controller for controlling the inverter of grid

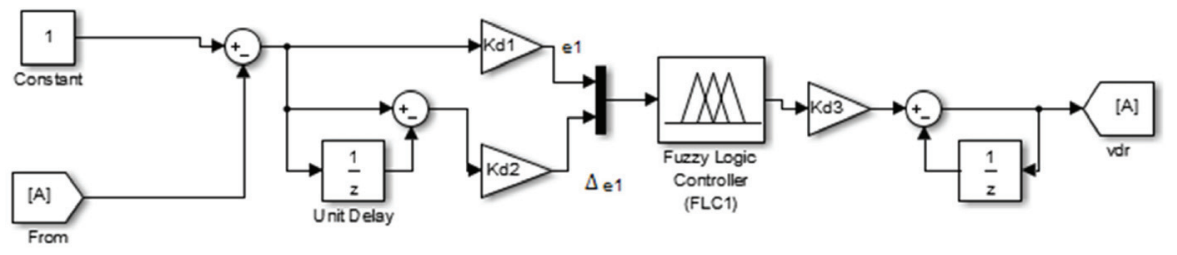

(a)

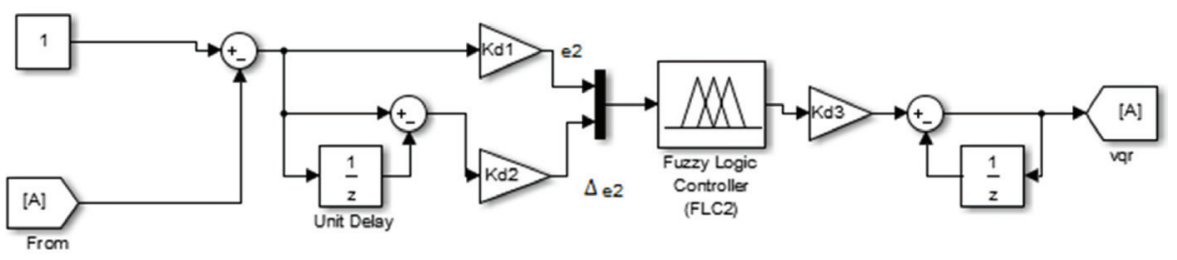

(b)

Figure 5 Control block of an FLC controlled inverter (a) for FLC1 (b) for FLC2. 
Table 2 Fuzzy rule table for FLC1 and FLC2

\begin{tabular}{clllllll}
\hline $\mathrm{e} 1, \mathrm{e} 2 / \Delta \mathrm{e} 1, \Delta \mathrm{e} 2$ & $\mathrm{NL}$ & $\mathrm{NM}$ & $\mathrm{NS}$ & ZO & PS & PM & PL \\
\hline NL & PL & PL & PM & PM & PS & PS & ZO \\
NM & PL & PM & PM & PS & PS & ZO & NS \\
NS & PM & PM & PS & PS & ZO & NS & NS \\
ZO & PM & PS & PS & ZO & NS & NS & NM \\
PS & PS & PS & ZO & NS & NS & NM & NM \\
PM & PS & ZO & NS & NS & NM & NM & NL \\
PL & ZO & NS & NS & NM & NM & NL & NL \\
\hline
\end{tabular}

connected. PMSG system. These scaling factors play a very important role in getting the desired output response during transient and dynamic states. In this paper the said scaling factors are considered as constant for simple controller design and are fixed by trial and error method.

\section{Simulation Results}

The proposed control strategy for the selected WECS rating is specified in Appendix A and it is modelled using MATLAB/Simulink software tool. The performance of the proposed FLC controller is validated and compared with the basic PI controller.

Figure 6(a), shows the state of charging (SOC) of battery. The grid voltage and grid current for PI based control strategy is shown in Figure 6(b). A three phase to ground fault for $0.1 \mathrm{sec}$ during from $0.1 \mathrm{sec}$ to $0.2 \mathrm{sec}$ is applied to the system and it shows the grid voltage is reduced to $80 \mathrm{~V}$, distorting the SOC, current and distort the dc link voltage which lead to generator in inoperative mode of operation.

Figure 7(a) shows the SOC of battery when the proposed system is connected to FLC based control strategy. The battery is charged in linear manner without any distortion in voltage and current as exist in PI controller. Thus, protecting the battery from damage and increasing the life of battery.

When the FLC based control strategy is implemented in the grid connected WECS, a three phase ground fault is introduced at $0.1 \mathrm{sec}$ for the period of $0.1 \mathrm{sec}$. the grid voltage is reduced to $367 \mathrm{~V}$ as shown in Figure 7(b). Whereas, the grid voltage dipped to $80 \mathrm{~V}$ for PI based controller strategy during the same fault condition.

To examine the effectiveness of the proposed FLC controlled inverter, symmetrical 3-phase to grid fault is introduced as the network disturbance. In this study wind turbine is in dynamic operation and produce constant DC 


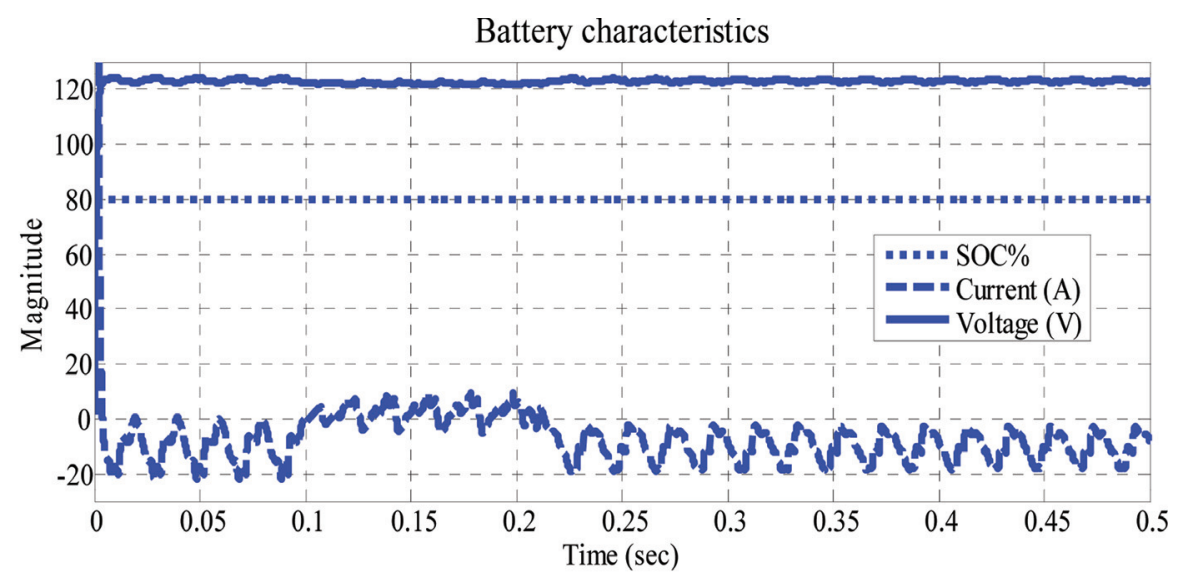

(a)
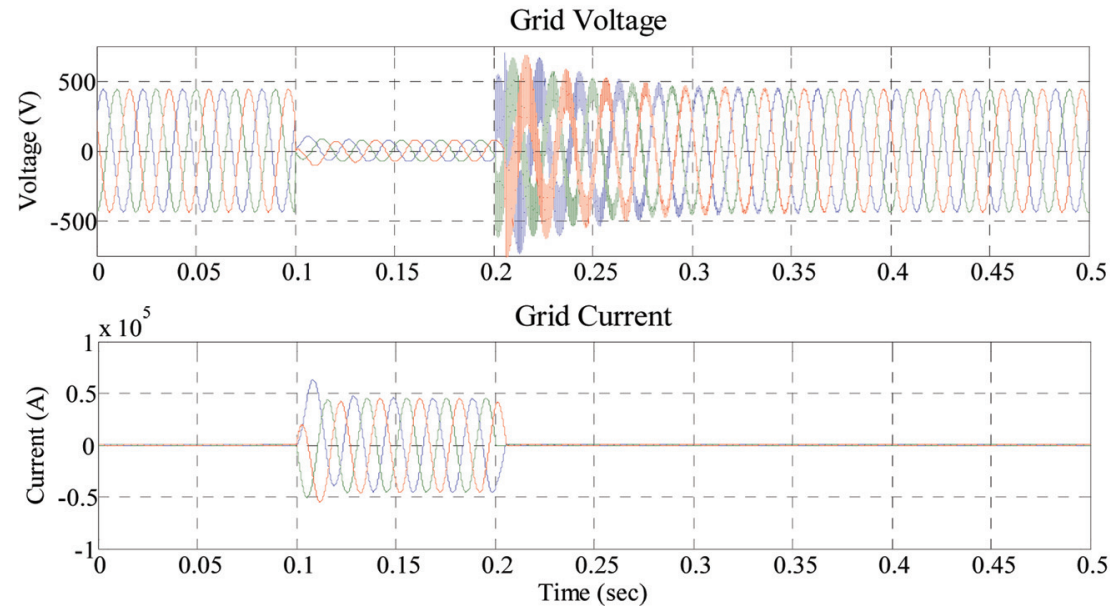

(b)

Figure 6 (a) Battery state of charge for PI based controller (b) Grid voltage and grid current for PI control based grid interfacing under fault condition.

output through the FLC controlled boost converter. Both rotor side and grid side FLCs along with HCC controlled inverter provide required power during the network disturbances. Hence, the grid voltage returns to its pre-fault level as given in Figure 7(b) with the help of both the controllers. But the proposed FLC inverter helps to reach real and reactive power very quickly with better performance without oscillation especially during transients. From the results 


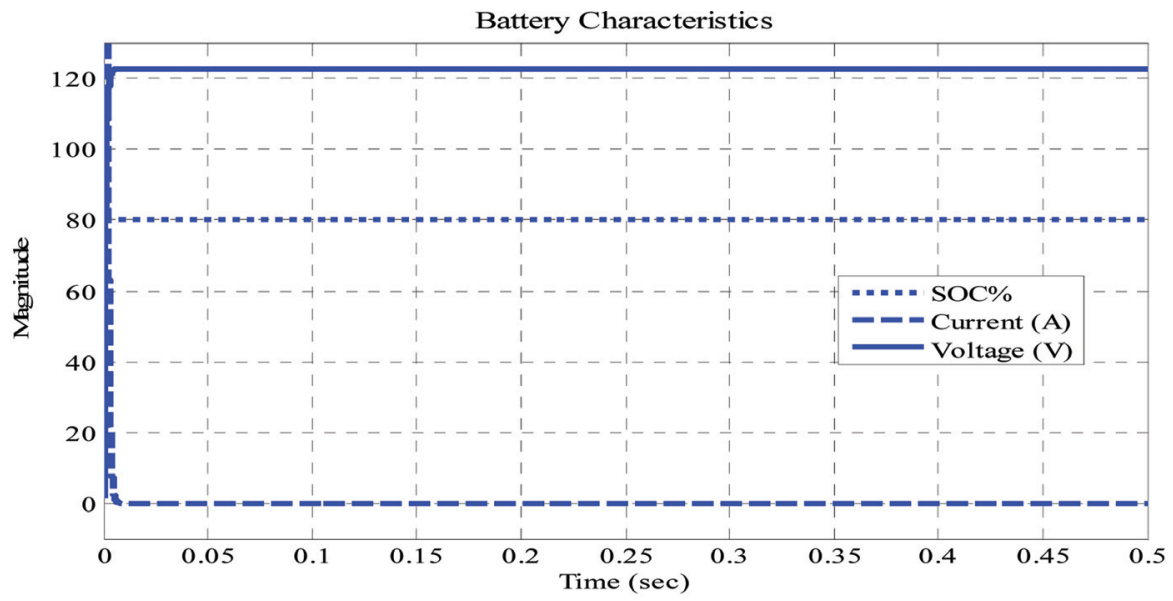

(a)
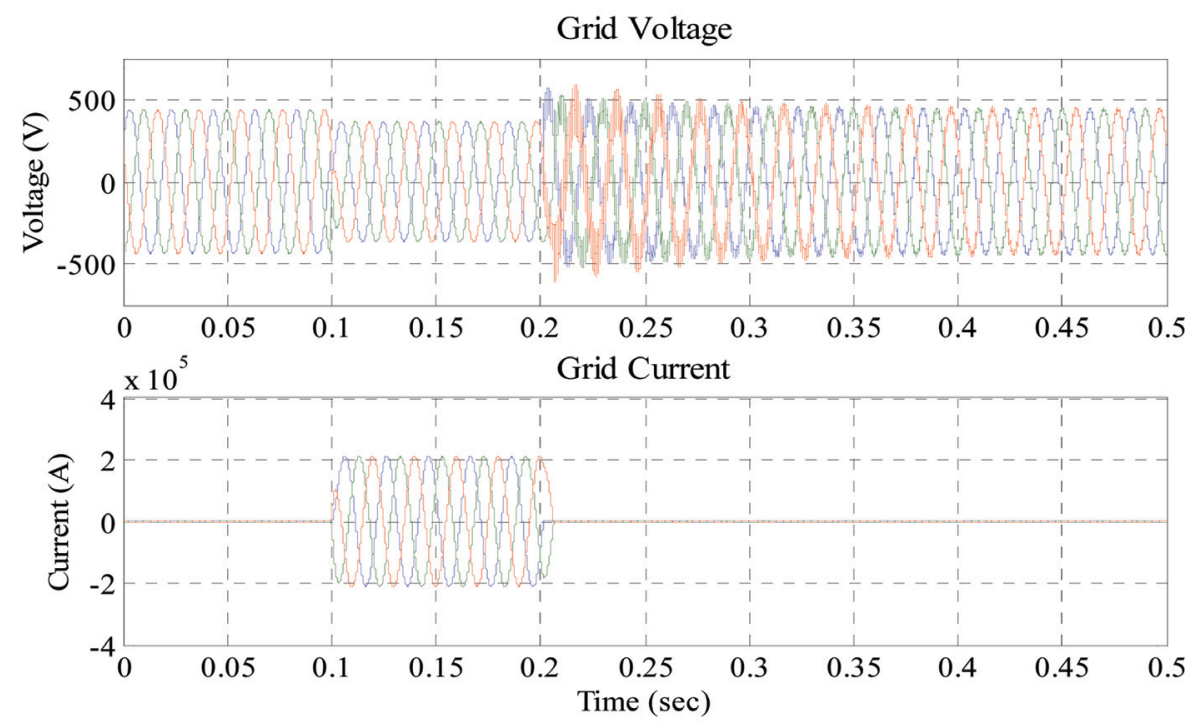

(b)

Figure 7 (a) Battery state of charge for fuzzy based controller (b) Grid voltage and grid current for fuzzy control based grid interfacing under fault condition.

it is absorbed that the proposed FLC along with HCC controlled inverter design provides better results in the case of DC link voltage and holds the system at acceptable level. 


\section{Conclusion}

This paper presents dynamic modelling of WT, modelling of grid connected PMSG and FLC based MPPT controller for VSWT-PMSG and implemented in MATLAB. The direct driven PMSG based WECS along with controller action maintains constant power output. The FL based MPPT controller in the boost converter converts the variable DC output voltage from the PMSG to a constant DC voltage of $122 \mathrm{~V}$ which is given to the energy storage system.

This paper also proposes the FL based controller for grid side inverter which is suitable for variable speed wind turbine with PMSG. The performance of the overall system was validated and compared with the conventional PI control for GSI. Finally it is concluded that the proposed FLC for both rectifierboost converter and HCC inverter be the good option for the grid connected wind energy conversion system.

Appendix. A

\begin{tabular}{ll}
\hline \multicolumn{1}{c}{ Wind Turbine Generator System Parameters } \\
\hline Stator phase resistance Rs (ohm) & $1.25 \mathrm{ohm}$ \\
Armature inductance (H) & $0.325 \mathrm{mH}$ \\
Flux linkage & 0.21134 \\
Torque constant & 1.9021 \\
Voltage constant & $230 \mathrm{~V}$ \\
Frequency (Hz) & $50 \mathrm{~Hz}$ \\
Pole pairs & 6 \\
Rated power & $3.3 \mathrm{kw}$ \\
\hline \multicolumn{2}{c}{$\quad$ DC Link } \\
\hline DC link voltage V & $122 \mathrm{~V}$ \\
Capacitor (C) & $10 \mathrm{mF}$ \\
Inductor (L) & $0.156 \mathrm{mH}$ \\
\hline \multicolumn{1}{c}{$\quad$ Energy Storage System Parameters } \\
\hline Nominal mechanical power output (W) \\
Base wind speed (m/s) & $3300 \mathrm{~W}$ \\
Pitch angle beta (deg) & $12 \mathrm{~m} / \mathrm{s}$ \\
Maximum power at base wind speed (pu) & 0 \\
\hline \multicolumn{2}{c}{ Lead Acid } \\
\hline Battery type & $120 \mathrm{~V}$ \\
Nominal Voltage (V) & $15 \mathrm{Ah}$ \\
Rated Capacity (Ah) & 80 \\
Initial State-Of-Charge (\%) & 15.625 \\
Maximum Capacity (Ah) & $115 \mathrm{~V}$ \\
Fully Charged Voltage (V) & $3 \mathrm{~A}$ \\
Nominal Discharge Current (A) & $0.08 \mathrm{Ohms}$ \\
Internal Resistance (Ohms) & \\
\hline
\end{tabular}




\section{References}

[1] Saravanan, S., and Ramesh Babu, N. (2016). Maximum power point tracking algorithms for photovoltaic system - a review. Renew Sustain Energy Rev. 57, 197-204.

[2] Babu, N. R., and Arulmozhivarman, P. (2013). Wind energy conversion systems - a technical review. J. Eng. Sci. Technol. 8, 493-507.

[3] Tiwari, R., and Babu, N. R. (2016). Recent developments of control strategies for wind energy conversion system. Renew Sustain Energy Rev. 66, 268-285.

[4] Hannan, M. A., Ghani, Z. A., Mohamed, A., and Uddin, M. N. (2015). Real-time testing of a fuzzy-logic-controller-based grid-connected photovoltaic inverter system. IEEE Trans. Ind. App. 51, 4775-4784.

[5] Zhang, S., Tseng, K. J., Vilathgamuwa, D. M., Nguyen, T. D., and Wang, X. Y. (2011). Design of a robust grid interface system for PMSG-based wind turbine generators. IEEE Trans. Ind. Electron. 58, 316-328.

[6] Eltamaly, A. M., and Farh, H. M. (2013). Maximum power extraction from wind energy system based on fuzzy logic control. Electric Power Syst. Res. 97, 144-150.

[7] Macarulla, M., Albano, M., and Ferreire, L. L. (2016). Lesson learned in building a middleware for smart grid. J. Green Eng. 6, 1-26.

[8] Bendiabdellah, Z., Sedjelmaci, H., Attia, M., Senouci, S. M., and Feham, M. (2016). Interaction of electric vehicle and smart grid based on game theory for smoothining peak load and $\mathrm{CO} 2$ reduction. J. Green Eng. 6, $51-76$.

[9] Kabalci, Y. (2016). A survey on smart metering and smart grid communication. Renew. Sustain. Energy Rev. 57, 302-18.

[10] Yin, X.-X., Lin, Y.-S., Li, W., Gu, Y.-J., Lei, P.-F., and Liu, H.-W. (2015). Fuzzy-logic sliding-mode control strategy for extracting maximum wind power. Int. J. Elect. Power Energy Syst. 70, 45-51.

[11] Van, T. L., Nguyen, T. H., and Lee, D.-C. (2015). advanced pitch angle control based on fuzzy logic for variable-speed wind turbine systems. IEEE Trans. Energy Conver. 30, 578-587.

[12] Muyeen, S. M., and Al-Durra, A. (2013). Modeling and control strategies of fuzzy logic controlled inverter system for grid interconnected variable speed wind generator. IEEE Syst. J. 7, 817-827.

[13] Bellatreche, H., Bounekhla, M., and Tlemcani, A. (2016). Using Fuzzy logic and hystersis current control to reduce harmonics in three level NPC shunt acting power filter. Int. Conf. Model. Identi. Control. Algiers. $5-9$. 
[14] Tiwari, R., and Babu, N. R. (2016). Fuzzy logic based MPPT for permanent magnet synchronous generator in wind energy conversion system. IFAC Papersonline 49, 462-467.

[15] Abdullah, M. A., Yatim, A. H., Tan, C. W., and Saidur, R. (2012). A review of maximum power point tracking algorithms for wind energy systems. Renew Sustain Energy Rev.16, 3220-3227.

[16] Muyeen, S. M., Takahashi, R., Murata, T., and Tamura, J. (2010). A variable speed wind turbine control strategy to meet wind farm grid code requirements. IEEE Trans. Power syst. 25, 331-340.

[17] Al-Turki, Y. A., Attia, A. F., and Soliman, H. F. (2012). Optimization of fuzzy logic controller for supervisory power system stabilizers. Acta Polytechn. 52, 2.

[18] Baroudi, J. A., Dinavahi, V., and Knight, A. M. (2007). A review of power converter topologies for wind generators. Renew. Energy 32, 2369-2385.

[19] Calderaro, V., Galdi, V., Piccolo, A., and Siano, P. (2008). A fuzzy controller for maximum energy extraction from variable speed wind power generation systems. Electric Power Syst. Res. 78, 1109-1118.

[20] Aissaoui, A. G., Tahour, A., Essounbouli, N., Nollet, F., Abid, M., and Chergui, M. I. (2013). A Fuzzy-PI control to extract an optimal power from wind turbine. Energy Conver. Manag. 65, 688-696.

[21] Adhikari J., Prasanna, I. V., Ponraj, G., and Panda, S. (2016). Modelling, design, and implementation of a power conversion system for smallscale high altitude wind power generating system. IEEE Trans. Ind. App. 26:4388.

[22] Kamel, R. M. (2016). New inverter control for balancing standalone micro-grid phase voltages: A review on $\mathrm{MG}$ power quality improvement. Renew. Sustain. Energy Rev. 63, 520-532.

[23] Allik, A., Märss, M., Uiga, J., and Annuk, A. (2016). Optimization of the inverter size for grid-connected residential wind energy systems with peak shaving. Renew. Energy 99, 1116-1125.

[24] Beddar, A., Bouzekri, H., Babes, B., and Afghoul, H. (2016). Experimental enhancement of fuzzy fractional order PI+I controller of grid connected variable speed wind energy conversion system. Energy Conver. Manag. 123, 569-580. 


\section{Biographies}

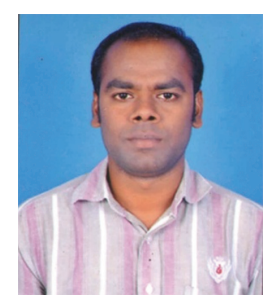

Velappagari Sekhar, is a Ph.D student at VIT University since 2014. He received his Bachelor's degree in Electrical and Electronics Engineering in the year 2008 from Siddhartha Institute of Engineering Technology, Puttur and Masters degree in Power System Engineering from Velammal Engineering College, Anna University, Chennai in the Year 2010. His research includes Renewable energy, Power Electronics and Control Optimisation techniques for renewable energy.

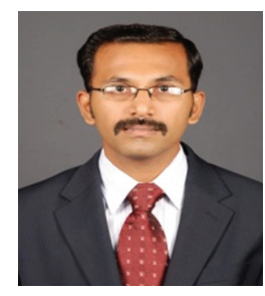

N. Ramesh Babu is a Associate Professor and Head in Department of Electrical and Instrumentation Engineering at VIT University, Vellore. He completed his B.E. degree in Electrical and Electronics Engineering from Bhartiyar University and M.E. degree in Applied Electronics from Anna University. He completed his Ph.D degree from VIT University. He has authored and co-authored more than 50 publication in reputed International Journal and conferences. His research area includes Wind speed forecasting, Optimal control of wind energy conversion system, Solar energy, Power Electronics, Control \& Signal Processing and Application of Soft Computing techniques in Electrical Engineering. 